\title{
An Accuracy Investigation of Product Cost Estimation in Automotive Die Manufacturing
}

\author{
Julia Bendul ${ }^{1} \&$ Vasile Apostu ${ }^{2}$ \\ 1 Julia Bendul, Chair for the Management of Digitalization and Automation, RWTH Aachen University, \\ Kackertstraße 7, 52072 Aachen, Germany \\ ${ }^{2}$ Vasile Apostu, Workgroup Production and Logsitics Networks, Jacobs University Bremen, Campus Ring 1, 28759 \\ Bremen, Germany \\ Correspondence: Julia Bendul, Chair for the Management of Digitalization and Automation, RWTH Aachen \\ University, Kackertstraße 7, 52072 Aachen, Germany.
}

Received: September 4, 2017

Accepted: October 9, 2017

Online Published: October 26, 2017

doi:10.5430/ijba.v8n7p1

URL: https://doi.org/10.5430/ijba.v8n7p1

\begin{abstract}
Automotive die manufacturers face the constant challenge of producing qualitative products while having to reduce costs. However, cost reduction measures are rather insignificant during the actual manufacturing process as the most important cost-impacting decisions are taken during the design phase. Cost estimation methods attempt to determine the production cost already in the design phase; the cost can be broken down and therefore the plan times of manufacturing processes can be pre-calculated, thus enabling early capacity decisions. Many researchers have been focusing for decades on developing efficient cost estimation methods. Yet their scarce access to cost information meant that most of the developed methods could not be evaluated with real data and thus their implementation in practice being challenged. This paper reviews and classifies cost estimation methods and investigates the accuracy of the estimate based onpractical application in 190 cases. The overall aim is to determine the accuracy level of the studied methods in practice and therefore identify their application fields.
\end{abstract}

Keywords: die manufacturing, cost estimation, accuracy, validation, choice of methods

\section{Introduction}

The economy has developed rapidly and in such a manner that requires companies across all industries to deliver in a much shorter time, with a similar or better quality and, at the same time, for a lower price (Chen \& Chen, 2002; Weustink, et al., 2000; Nagahanumaiah, et al., 2005). Nowadays, companies struggle even more than in the past to remain competitive while still being profitable.

The products and production processes of die manufacturing are very complex since dies are manufactured within job-shops. The uniqueness of the parts does not allow the implementation of a more efficient line or flow production (Eversheim \& Klocke, 1998). Due to its high complexity and the orientation towards a sequential engineering approach (Syan \& Menon, 1994), any changes originally aimed at cost reduction that are implemented during the manufacturing stage could in some cases lead to a cost increase instead, due to the necessity to redo certain steps that had been already completed. Therefore, production companies should consider all aspects of the development and production of the product, including the need for cost reduction, already during the design phase of the respective product and before any decision towards the manufacturing is taken, an approach known as concurrent engineering (Syan \& Menon, 1994). Taking measures early in the design phase can influence between $70-90 \%$ of the final product costs (Chen \& Chen, 2002).

In order to act early in the design phase and reduce costs, project managers have to be able to estimate the costs that would otherwise result from the respective design and manufacturing plan, including any possible changes that might occur (Jiao \& Tseng, 1999; Zhang \& Fuh, 1998). Nevertheless, only when the estimate is accurate will project managers be able to effectively influence the final product cost through design changes. Furthermore, deriving plan process times from the estimated cost enables an early capacity planning. However, decisions based on inaccurate values would lead to issues in utilization. As a result, our research focus strives to ensure a high accuracy level of the cost estimation methods applied. This, in turn, requires researchers to compare the outputs of scientific estimation 
methods against real cost information from the industry.

This paper aims at critically reviewing existing cost estimation methods in the die manufacturing sector. This includes the investigation and classification of different methods in respect of their accuracy by means of a set of 190 data sets from die manufacturing industry. Our research is beneficial for production managers and researchers in the field by developing initial recommendations on how to choose the optimal cost estimation method based on product and producer characteristics and to make realistic cost estimates.

The article will first provide a theoretical background of concurrent engineering and of cost estimation. We will present a classification of existing cost estimation methods and analyse to what extent they have been tested in industrial practice. We select a set of cost estimation methods which is then tested by means of an industry data.

\section{State of the Art}

\subsection{Die Manufacturing}

The production of customized goods is still in continuous need of support from researchers. Through the uniqueness of the products, die manufacturing is also part of the niche known as versatile manufacturing (Kingsman \& Souza, 1997). As opposed to serial production, where the optimal design and environment settings have to be determined once only for a large batch size, die manufacturers have to design and set up the production process for each unit of product they produce (Kingsman \& Souza, 1997). Consequently, the challenge to produce dies more cost efficiently increases constantly due to the market and innovation pressure.

Dies are assemblies that are used in a press-shop to stamp various parts out of sheet metal. The complexity of the die depends on a plethora of factors, ranging from the geometry of the part to the material it is made of (Eversheim \& Klocke, 1998). The stamping process of a part can be performed in several steps (Figure 1), depending on the complexity of the surface. For each of these steps, a unique die will be required: Therefore for each part, a unique set of dies has to be produced (Schuler, 1998). This results in a high number of dies being needed for each individual vehicle model; variations of the body would call for further die sets. Despite the respective dies being similar to each other or to others produced in the past, the cost differences can still be high and the die manufacturer needs to invest effort in every single product for every single customer individually (Kingsman \& Souza, 1997).

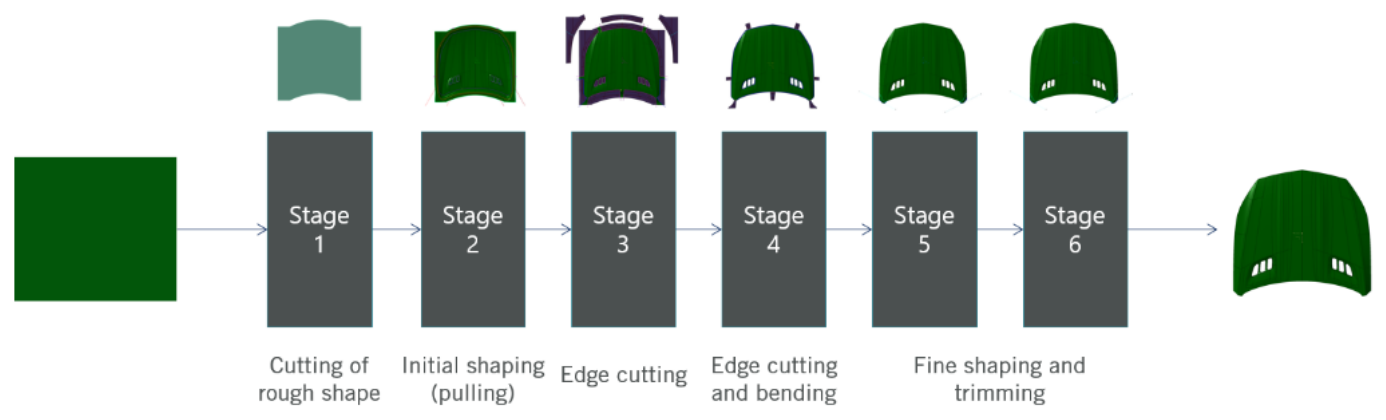

Figure 1. Pressing stages on the example of a car engine hood

A typical die consists of an external structure and an internal design. The external structure is a two piece cast frame, top and bottom, which is designed as a support for the internal elements of the die and also facilitates the set up of the die within the press. The internal design is the functional part of a die and consists of an assembly of several parts and sub-assemblies that are produced through various machining processes within a job-shop (Tumis, 2007). Each part is created out of a solid block of raw material by removing metal through different procedures, such as milling, drilling and turning, depending on the geometry of the final part (Schuler, 1998). The procedure is established by the type of features determined by the geometry of the part. 


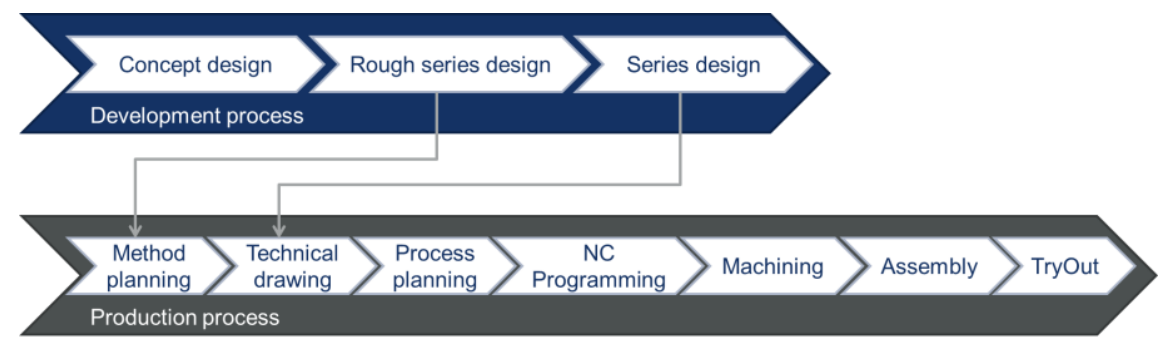

Figure 2. Overview of the die manufacturing process

The die manufacturing process consists of seven stages, as portrayed in Figure 2. Based on the part that the die set will produce, the geometry of the die is determined as well as the required number of stamping steps, refered to as the stamping method. This is followed by a technical design stage where each die is minutiously developed in CAD. Based on the technical details, the production processes for each component as well as the assembly process can be planned. Further, the NC programs for the machining are created, followed by the actual machining within the job-shop. As soon as all parts are available, the die is assembled and tested to determine and improve the part quality (Eversheim \& Klocke, 1998).

Moreover, die manufacturing is split into two major groups: internal and external. Automotive OEMs have in most cases their own die shop on site, known as internal die manufacturers. The market, however, also knows external die makers as stand-alone companies. Both internal and external die shops take part in the bidding process organized by OEMs. As soon as a die needs to be manufactured, a call for tenders is issued and the interested die manufacturers have the task to analyse the respective die and estimate the production cost in order to place a bid. Based on the respective bid and several other quality and reliability factors, the die manufacturer is selected and contracted (Schuh, et al., 2005). This shows how important generating the right estimates for the bid is. Too high an estimate would result in not getting the contract and the respective die maker would be underutilized. Too low an estimate, on the other hand, would increase the chances of being contracted, however the risk of incurring losses is high. Both cases are not economically viable for die makers, their survival on the market being at stake, therefore the process of generating accurate estimates for dies has been in focus for decades.

\subsection{Product Cost Estimation}

\subsubsection{Challenges of Product Cost Estimation in Die Manufacturing}

Product cost estimation is an area that has been challenging the minds of researchers since the early 1980s (Jha, 1992). Although the underlying idea of cost estimation is simple and easily comprehensible, its development and implementation has become more complicated over the years. The reason for the increasing complexity of the methods is the increased level of detail used to determine the manufacturing cost of a product as well as the accuracy of the calculation. In essence, product cost estimation attempts to realistically predict the costs required to manufacture a specific product before it is actually created (Wei \& Egbelu, 2000; Jha, 1992).

Cost estimation is an offshoot from cost accounting, which differs from the latter in two major aspects. First, cost estimation is performed before the product is manufactured. Second, cost accounting is performed by accountants who analyse the bills and resource usage to determine the product cost after production, while cost estimation is performed by experienced engineers who peruse their extensive knowledge of production technology and engineering economics in order to calculate the estimated cost of the product to be manufactured (Aderoba, 1997).

H'mida (2006) introduced the concept of cost entity which visualizes all the factors that have an influence on the final cost. The cost entity concept applies very well to die manufacturing as it relates to the machining and assembling operations involved in the production of dies and their respective cost drivers (H'mida, et al., 2006). Furthermore, cost estimation methods are, in essence, all based on this structure, despite their approaches differing significantly. 


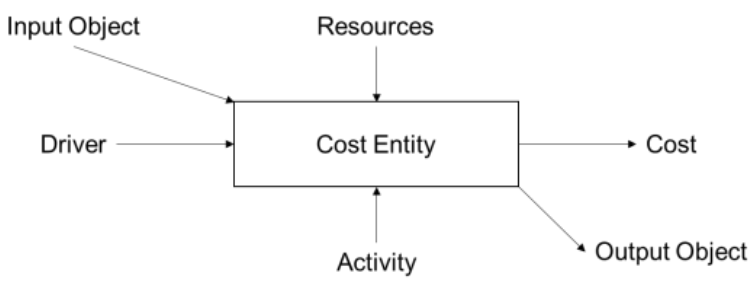

Figure 3. Cost entity (H'mida, et al., 2006)

In order to tackle the challenging task of cost estimation, a multitude of methods were developed by researchers during the past decade. Each approached the task from a different perspective, either looking at historical data or at the processes determined by the design of the part, and with various degrees of complexity. It is clear from the literature that cost estimation methods have developed over time and have become more complex while taking into account more information in order to better predict the cost of a product (Agyapong-Kodua, et al., 2011).

Firstly, basic parametric and analogical methods were established, followed by analytic cost estimation and later by activity-based cost estimation methods. During the past decade, researchers developed feature-based methods, which are more recently being advanced through case-based reasoning. However, a more structured classification of cost estimation methods is described by Verlinden based on the underlying approach of the methods, namely (Verlinden, et al., 2008):

- Variant-based methods take into account previously produced dies and estimate the cost of the new dies based on similarly manufactured products in the past. These methods analyse objectively the similarity between the parts and, based on the resulting coefficient, determine the amount of the costs of the analysed die (Verlinden, et al., 2008).

- Generative cost estimation methods determined the cost of the die based on its characteristics and the part it will produce. This sort of method analyses either the production processes, the geometry of the part or the features of the die in order to aggregately calculate the overall production costs (Verlinden, et al., 2008).

- Hybrid cost estimation methods combine the two approaches in order to use all the available knowledge regarding the die, aiming at estimating the manufacturing costs as accurately as possible. The specialised literature to date states that variant-based methods should supplement generative cost estimation when design information of certain parts is not yet available (Verlinden, et al., 2008). However, by using variant-based methods to support generative cost estimation even when design data is available could significantly improve the estimate as it involves historical experience in the calculation (Layer, 2003).

This chapter will further describe individually the abovementioned types of cost estimation methods as well as several underlying methods, revealing in this process the implications of implementing them within a die manufacturing environment.

Table 1. Overview of cost estimation methods grouped

\begin{tabular}{ccc}
\hline Variant-based & Generative & Hybrid \\
\hline Case-based & Activity-based & CABACO \\
Parametric & Feature-based & \\
\hline
\end{tabular}

\subsubsection{Variant-based Methods}

Variant-based methods encompass methods that identify a similar product that has already been produced and makes use of the respectively associated cost data in order to determine the cost of the desired part/product (Agyapong-Kodua, et al., 2011; Verlinden, et al., 2008). Researchers claim analogous methods are the best-established and most-used cost estimation methods in the industry (Agyapong-Kodua, et al., 2011; Curran, et al., 2004; Shepperd, et al., 1996; Shepperd \& Schofield, 1997). Curran (2004) documented several steps that could be followed in order to successfully implement an analogy-based method (Curran, et al., 2004). One would firstly identify and define in detail the product whose cost is to be estimated followed by establishing the data sources to be 
used. After the data collection, a set of factors are determined, i.e. factors which relate to the characteristics of the product that could influence its cost. Based on the identified factors, the cost is then estimated through association with previously produced parts (Agyapong-Kodua, et al., 2011; Curran, et al., 2004). This association is based on a similarity degree that can be determined through various algorithms ranging from manual expert evaluation, also known as expert judgement cost estimation, to complex algorithms (fuzzy logic, nearest neighbour etc.) (Shepperd \& Schofield, 1997). Parametric methods, on the other hand, analyse the product and identify the cost drivers. Using regression or statistical correlation analysis based on historical data, the influence of the recognised cost drivers on the manufacturing cost is determined. Further, these factors are included within the CER and thus are used for calculating the estimate (Agyapong-Kodua, et al., 2011; Curran, et al., 2004; Crawford, 1985).

Variant-based methods depend greatly on the accuracy of the data used as well as how precise the similarity measure is calculated (Agyapong-Kodua, et al., 2011). The higher the number of similarity factors that need to be considered, the higher is the complexity of the calculation and therefore the precision of the estimate is (Curran, et al., 2004; Shepperd \& Schofield, 1997).

Taking into account the uniqueness of the products of die manufacturing as well as the high complexity and therefore the high number of product features, variant-based methods are severely challenged and were not yet proven to deliver an accurate cost estimate. Attempts have been made towards implementing similarity measures that would bring case-based methods closer to the reality of die manufacturing; but as stand-alone methods, variant-based methods are still lacking in detail and precision (Layer, 2003).

\subsubsection{Generative Cost Estimation}

Generative cost estimation methods evaluate the cost of manufacturing a product based on the complexity of the product, the characteristics of its components as well as the production processes they will be subjected to (Agyapong-Kodua, et al., 2011). Activity-based methods have been developed to take into account the standard processes required to manufacture the product. Several methods of this type have been developed; however, they all are the same in their core. Activity-based approaches estimate the cost through an aggregation function of all the individual costs of the manufacturing processes of the respective part. This is determined through a multiplication of the machine cost rate with the processing time the part requires. The challenge that these approaches face lies in the accurate estimation of the processing time. This method still relies to a certain extent on expert intervention, but it does depict a clearer picture of the cost structure of the analysed product (Aderoba, 1997; Ong, 1995; Tornberg, et al., 2002; Ben-Arieh \& Qian, 2003; Boons, 1998; Schreve, et al., 1999).

Feature-based approaches come as a further development of activity-based approaches in the sense that the required processing time is determined in a more precise manner, without using human input or standard times. In principle, feature-based methods break down the analysed part into standard sections, referred to as features and, based on their geometry, the volume of the material to be removed is determined, which when put together with the properties of the machine used reveals the needed processing time. Further, the cost estimate is an aggregate of the individual processing costs, in a similar manner as with the activity-based approaches (Shehab \& Abdalla, 2001; Weustink, et al., 2000; Bouaziz, et al., 2004; Bouaziz, et al., 2006; Chin \& Wong, 1995; Wei \& Egbelu, 2000; Ben-Arieh, 2000; Ou-Yang \& Lin, 1997; Nagahanumaiah, et al., 2005; Jung, 2002).

Generative approaches were designed to account for more detail and attempt to make use of the available process information, which identifies well with the underlying principle of die manufacturing. Activity- and feature-based approaches have cast the path towards the standard cost estimation tool for dies and moulds, these being preferred as basis for estimation software. The process-oriented view of the methods complements the characteristics of die manufacturing. However, there are still standard values that are assumed for the calculation, the developed methods not taking into consideration deviations that could occur due to certain properties of the products in question.

\subsubsection{Hybrid Cost Estimation}

Hybrid approaches interlace, by definition, two or more types of cost estimation methods. The reasoning behind this method concatenation is not unique. According to Verlinden (2008), hybrid estimation is used very early in the design stage when not enough information is yet known. For some sections of the analysed part, detailed design information is available, leading to generative methods being used. However, other sections might only be developed at the time the estimate is calculated and therefore only variant-based methods can be used. This consensus of the two approaches would then make up the cost estimate for the respective product (Verlinden, et al., 2008; Brinke, et al., 2000).

However, Layer (2001) presents a method that is by definition hybrid, but is different from the perspective presented 
above. Instead of using variant-based methods to compensate for the lack of detailed information of a section of the product, the author uses case-based approaches for every section of the part, complementing the generative estimation. Instead of using standard information for each process that the part will be submitted to, the method looks at deviations that might have occurred in the past with similar products and uses that knowledge to improve the overall cost estimate (Layer, 2003).

Further solutions are being developed in the form of hybrid cost estimation methods. Not only are these established on the feature-based methods, assimilating the process-oriented view, but they enhance them by using historical knowledge matched through similarity measures to the part being analysed. This approach to cost estimation makes use of both known views towards cost estimation with the purpose of creating a more realistic and therefore more accurate estimate result. Methods pertaining to this category should theoretically perform the best estimates in the case of die manufacturing. The uniqueness of the parts will foster the generative side while the high number of features within a die could be the basis of application of variant-based approaches, thus making hybrid cost estimation the ideal category of methods to apply.

\subsection{Research Gap}

The investigation of accuracy requires a measure to be defined upon which all cost estimation methods will be compared. This indicator has to reflect the accuracy of each method, be consistent throughout the study, and for a better understanding and comparison with other fields, it should not depend on any scale. Thus, for the purpose of this paper the mean absolute percentage deviation (MAPD) will be used.

$$
\operatorname{MAPD}_{\mathrm{t}}=100 * \frac{\sum_{i=2}^{t} \frac{\left|e_{i}\right|}{D_{i}}}{t-1} \% \quad(\text { Christou, 2011) }
$$

For the current application case, $D_{i}$ would represent the actual recorded cost of the manufactured dies. The absolute difference between the estimated and actual cost is represented as the absolute error rate $\left|e_{i}\right|$. The indicator $t$ represents the number of estimations performed for a single product (Christou, 2011). This variable is used as multiple estimations are calculated at various time intervals and their accuracy as a combined estimation is required. The simplified formula for determining the accuracy of the analysed cost estimation methods within the current case study is the following:

$$
\mathrm{APD}=100 * \frac{\mid \text { actual cost-estimated cost } \mid}{\text { actual cost }} \%
$$

The MAPD is then calculated as a mean over the entire data set. Furthermore, in order to appraise the quality of the estimation method being investigated, the continuous MAPD indicator needs be translated into a categorical variable. In the field of cost estimation, the following evaluation of the MAPD value is common (Christou, 2011):

$\begin{array}{ccccccccccc}0 \% & 10 \% & 20 \% & 30 \% & 40 \% & 50 \% & 60 \% & 70 \% & 80 \% & 90 \% & 100 \% \\ \text { excellent } & \text { good } & \text { moderate } & \text { poor }\end{array}$

Let us consider the following hypothetical example for the purpose of illustrating the applicability of the abovementioned scale. Assume a die costs 350 cost units to produce. The utilised cost estimation method predicts a cost of 497 units. The MAPD in this case would be $42 \%$, meaning the method features a poor accuracy, which is understandable considering the 147 difference in cost. An accuracy level of $15 \%$ for example would mean that the cost estimation method predicts a cost of 402.5 units, overestimating the actual cost by 52.5 units. This puts into perspective the accuracy scale and is beneficial to die makers to determine which cost estimation they can implement taking into consideration the level of risk they are willing to take.

Table 2. Overview of reviewed cost estimation methods

\begin{tabular}{llllll}
\hline \multicolumn{2}{c}{ Variant-based } & \multicolumn{2}{c}{ Generative } & \multicolumn{2}{c}{ Hybrid } \\
\hline \multicolumn{1}{c}{ Author } & Accuracy test & \multicolumn{1}{c}{ Author } & Accuracy test & \multicolumn{1}{c}{ Author } & Accuracy test \\
\hline Bode, J. & no & Aderoba, A. & no & Layer, A. & no \\
Bode, J. & no & Beck, U. & no & Ten Brinke, E. & no
\end{tabular}




$\begin{array}{llll}\text { Cavalieri, S. } & \text { attempted } & \text { Ben-Arieh, D. } & \text { no } \\ \text { Chan, D.S.K. } & \text { no } & \text { Bidanda, B. } & \text { no } \\ \text { Chen, M. } & \text { attempted } & \text { Boons, A. } & \text { no } \\ \text { Chin, K. } & \text { no } & \text { Bouaziz, Z. } & \text { no } \\ \text { de Cos, J. } & \text { attempted } & \text { Bouaziz, Z. } & \text { no } \\ \text { Deng, S. } & \text { attempted } & \text { Chin, K. } & \text { no } \\ \text { Duran, O. } & \text { no } & \text { Eaglesham, M. } & \text { no } \\ \text { Duverlie, P. } & \text { attempted } & \text { Fischer, J. } & \text { no } \\ \text { Eklin, M. } & \text { attempted } & \text { Haffner, S. } & \text { no } \\ \text { Luong, L.H.S. } & \text { no } & \text { Han, J. } & \text { no } \\ \text { Madmoudi F. } & \text { attempted } & \text { H'mida, F. } & \text { no } \\ \text { Özcan, B. } & \text { attempted } & \text { Jiao, J. } & \text { attempted } \\ \text { Qian, L. } & \text { attempted } & \text { Jung, J. } & \text { no } \\ \text { Son, Young K. } & \text { no } & \text { Nagahanumaiah } & \text { yes } \\ \text { Ten Brinke, E. } & \text { no } & \text { Ong, N.S. } & \text { attempted } \\ \text { Verlinden, B. } & \text { attempted } & \text { Ou-Yang, C. } & \text { no } \\ \text { Wang, H. } & \text { no } & \text { Schreve, K. } & \text { no } \\ \text { Wang, Q. } & \text { no } & \text { Shehab, E.M. } & \text { no } \\ \text { Watson, P. } & \text { no } & \text { Tomberg, K. } & \text { no } \\ \text { Weckman, G. } & \text { no } & \text { Wei, Y. } & \text { no } \\ & & \text { Weustnik, I.F. } & \text { no } \\ & & \text { Ye, J. } & \text { no } \\ & & \text { Zhang, Y.F. } & \text { attempted } \\ & & \end{array}$

\subsection{Research Gap}

The investigation revealed that out of the 49 articles identified only one author succeeded in validating the developed cost estimation in practice, albeit on a single limited data set containing a low number of products and featuring a moderate accuracy of the method (Nagahanumaiah, et al., 2005). Moreover, 12 further articles documented an attempt at validating their method. However, they were unable to confirm the accuracy of their method either, due to a too small data sample, or the method, or to the high error rate obtained. Furthermore, Bode mentions that they were unable to use real cost information to attempt to validate his developed approach (Bode, 2000). Nevertheless, in some cases, some authors made use of a simulation procedure, attempting to emulate the cost information from a production setting to enable them to test the accuracy of their method (Bode, 2000). The results of the literature review on accuracy testing in cost estimation have been summarized in table 2, showing which author has developed which type of cost estimation method and whether a validation was attempted or not.

\section{Accuracy Investigation}

\subsection{Approach}

The aim of this paper is to determine to what extent the currently developed methods have been implemented into practice and what level of accuracy they are providing. As established in the previous chapters, inaccurate cost estimates have the potential to lead die manufacturers into unprofitability; therefore it is of significance to determine to what extent the currently developed methods are fit for their intended application. This leads to the underlying theoretical motivation, namely identifying the need for either more accurate or dedicated cost estimation methods. The first sub-chapter features a literature research to determine what quota of the developed cost estimation methods has already been validated by the respective research scholars. Second, as an extension of the first section, a set of cost estimation methods was applied to an industry data set in order to ascertain the accuracy of the respective methods when applied in practice. The last sub-chapter is presented in the form of a discussion section where the 
findings are discussed together with their consequences for the research focus in cost estimation.

The literature review revealed that a scarcity of industry data makes any investigation in respect of the accuracy of cost estimation methods nearly impossible. Nevertheless, such an investigation using practical data would show the precision of the methods as well as reveal their sector of applicability. To fulfil this purpose, this article makes use of an industry database originating from an internal automotive die manufacturer. The data collected includes cost, design and production process information concerning 190 dies, spanning uniformly five different types of parts (door panels, structurural door elements, standard/panorama roofs and others). Although the data set is not extensive, it does provide a solid base for an accuracy investigation as it features a homogeneous mix of different die types, car models, and parts. The data set originates from a single industry partner, however the entire production process as well as the die design is based on norms and international standards, thus ensuring the general applicability of the study. Data was collected from a variety of sources, ranging from production planning and control software, 3D-designs, bill of materials, to die specification documents. Furthermore, additional insight was gained through interviews with production planners, production supervisors, and design engineers. All information was collected within an extensive database and the data was checked for inconsistencies.

This paper investigates the accuracy of four different cost estimation methods, namely expert judgement, parametric, activity-based, and feature-based cost estimation. In this manner, the two major categories, variant-based and generative cost estimation, are represented in the study. The selected methods are most frequented in the literature, have been developed extensively on a theoretical level and would provide a solid feedback in respect of the accuracy of the most common cost estimation procedure. Furthermore, the selected methods have high applicability potential in an industry environment and thus testing their accuracy in practice would have high relevance not only for the literature, but also for industry. Hybrid cost estimation methods are still scarcely described in the literature, methodologies for their application currently not being developed enough to render such methods fit for practical applications. As a result, this paper will not take into consideration at hybrid cost estimation methods. However, future research will approach developing application methodologies and test the feasibility of hybrid estimation methods for die manufacturing.

\subsection{Application of Cost Estimation Methods Using Industry Data}

This sub-chapter will describe in a detailed manner the practical implementation of each method on the available data set. The obtained accuracy level (MAPD) for each cost estimation method will be reporter respectively.

\subsubsection{Expert Judgement}

The suggestive nomenclature of this cost estimation method reveals a prerequisite that needs to be fulfilled: cost estimation using this method requires experts from the respective field who analyse the new part in detail and based on their experience subsequently arrive at a cost estimate. Within the current study, we interviewed an expert from the aforementioned die manufacturer who has been acting as a cost and process planner for the past 10 years. The 190 available dies were analysed and compared with previously produced press-tools followed by the derivation of the cost estimates. When comparing the estimates with the costs incurred in practice for each of the analysed dies, an average MAPD of $27.3 \%$ is obtained, rating it as a moderate estimation result.

\subsubsection{Parametric Cost Estimation}

The application of the parametric cost estimation method requires a more in-depth view of die manufacturing, focusing on the die design and characteristics. For this type of cost estimation method, several parameters are identified through research, experience, and expert interviews. Further, statistical analysis determines which parameters have a significant influence on the cost of the dies. The selected predictors are tested for pairwise correlations, with the purpose of eliminating redundant estimators that would only lead to increased effort for data collection and not improve the accuracy of the method. The respective parameters are then used as main cost driver for determining the CER. In this procedure, each parameter is assigned a coefficient. This leads to a simple calculation of the costs based on the value of the parameter for each die.

Table 3. Parameters for die cost estimation

\begin{tabular}{|c|c|c|}
\hline Parameter & $\mathrm{R}^{2}$ & p-value \\
\hline die type & 0.334 & 0.1007 \\
\hline panel type & 0.0107 & 0.2280 \\
\hline
\end{tabular}




\begin{tabular}{lll} 
number of parts being stamped at once & 0.2813 & 0.0000 \\
part type & 0.4129 & 0.0000 \\
die length & 0.4818 & 0.0000 \\
die width & 0.2978 & 0.0000 \\
die height & 0.1696 & 0.0000 \\
part material & 0.4974 & 0.0000 \\
part thickness & 0.3789 & 0.0000 \\
press & 0.0737 & 0.0057 \\
press rate & 0.0487 & 0.0093 \\
standard cams & 0.1045 & 0.0001 \\
rotational cams & 0.0082 & 0.2917 \\
cutting segments & 0.0709 & 0.0016 \\
\hline
\end{tabular}

Table 3 portrays the parameter table used for the current study along with their significance ( $\mathrm{p}$-value) and the influence strength $\left(\mathrm{R}^{2}\right)$. The pair-wise correlation analysis as well as refining attempts of the method led to the following parameters being used for cost estimation: the number of parts being stamped at once, part type, die length, die height, die width, part material, number of cams, press rate, and number of cutting segments. The estimation procedure using this approach returned a good accuracy result with an average MAPD of $19.6 \%$.

\subsubsection{Activity-based Cost Estimation}

The data set obtained from the industry partner contains not only cost and design information but also data towards the production processes. This enables application of the activity-based cost estimation. Implementing this method requires a knockdown of the respective dies into their sub-assemblies and individual components. The identified parts are produced by machining the required shape from a raw block of material. The machining process involves two variables that are necessary for the cost estimation process. The activity cost driver (ACD) is represented by the amount of time the process takes while the activity cost driver rate (ACDR) denominates the hourly cost rate of the respective machine. Therefore, knowledge of the machine park of the job-shop where the dies are being processed plays an important role in the cost estimation process. The cost of the process/activity (AC) is determined through the multiplication of the two variables (Ben-Arieh \& Qian, 2003). This study makes use of the industry partner's standards for production in the sense that the dies are knocked down into standard elements which have standardized processing times on selected machines. The cost rate for each machine is known and therefore the manufacturing cost is determined. The cost of the raw material is determined according to the dimension of the die and its components according to the market price at the time the study was performed. Additionally, the costs for testing the dies, which form part of the overall cost, was determined using parametric estimation. The effort invested in the implementation of the activity-based method is rewarded with an average MAPD value of $28.6 \%$, classifying the estimation method as exhibiting moderate accuracy.

\subsubsection{Feature-based Cost Estimation}

Feature-based cost estimation developed from the activity-based approach and differentiates itself through the method of determining the manufacturing times. A feature-based method analyses objectively each of the manufacturing features of every component, determines the volume to be machined and, using machine parameters, calculates the manufacturing time. The industry data set used for this investigation contains CAD information for each die. This data was minutiously analysed and the features of each individual component as well as the accordant manufacturing process and specific characteristics were identified. This entailed analysis of over 11,000 components and their features. The results were aggregated and the estimation returned an accuracy level (MAPD) of 20.1\%, rating it is a good cost estimation method.

\subsection{Discussion of Results}

The accuracy investigation performed for the purpose of this paper supplements the few attempts documented in the literature and, for the applied data set, depicts the level of accuracy the analysed methods exhibit. The results indicate clearly that from the selected set of methods activity-based cost estimation is on average the most accurate of the three. 

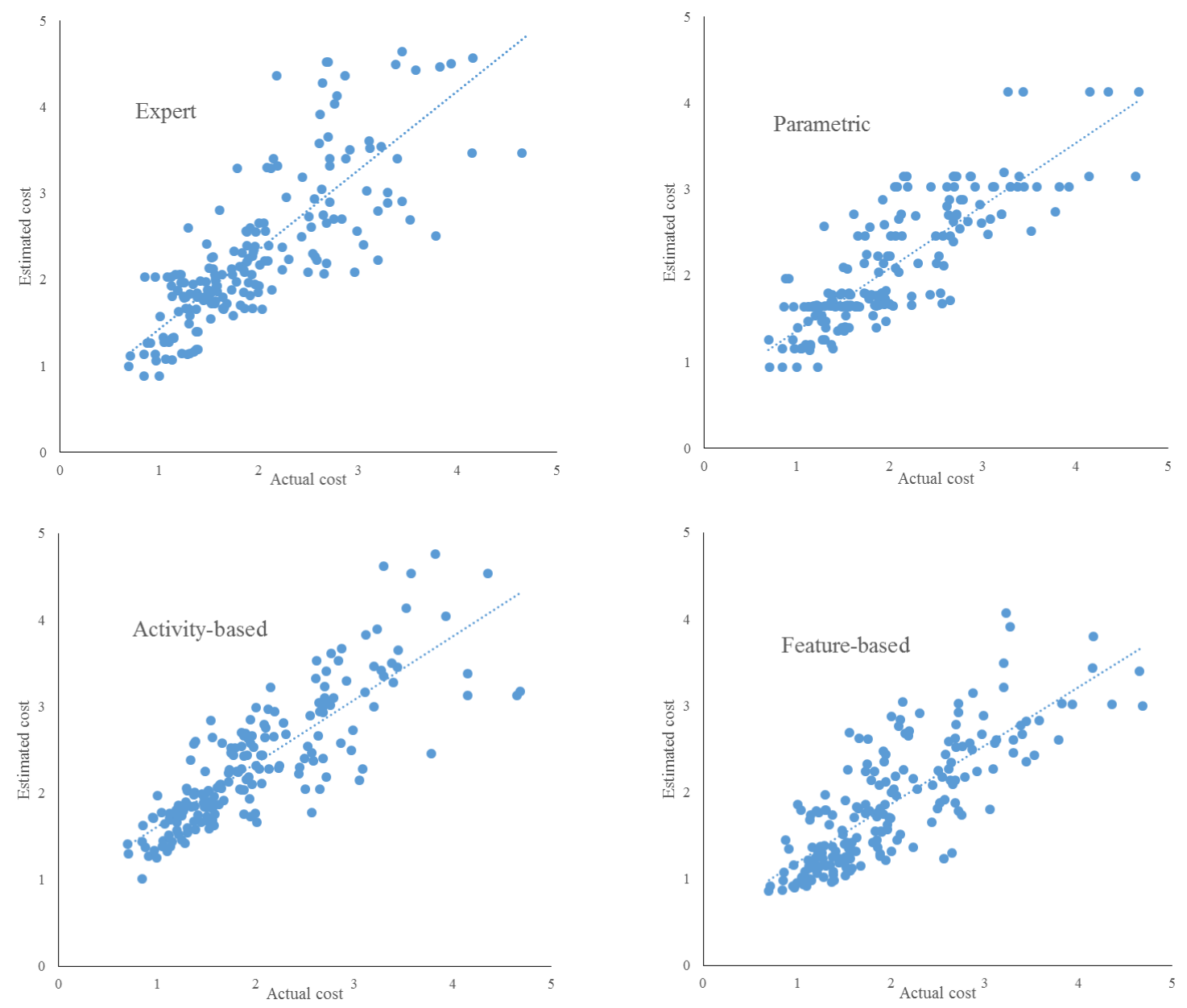

Figure 4. Estimated vs. actual costs

However, a more detailed insight into the accuracy levels of the respective methods reveals an interesting perspective. Figure 4 plots the results of estimation of each cost estimation method against the actual cost for each of the 190 dies available in the data set, results summarised in Table 4 additionally. Due to confidentiality concerns, the costs have been scaled down to values between 1 and 5 , and anonymized through the entire data set. The results are supplemented by the plot of the percentage deviation (Figure 5), which shows that on average all methods but feature-based methods overestimate the manufacturing cost. Furthermore, Figure 6 depicts the distribution of the tracking signal for all of the analysed methods, revealing the improvement potential of each method in the form of eliminating the existing bias in the estimation.

Table 4. Overview of accuracy of the investigated cost estimation methods

\begin{tabular}{lcccc}
\hline & Expert judgement & Parametric & Activity-based & Feature-based \\
\hline $\mathrm{R}^{2}$ & 0.66 & 0.71 & 0.69 & 0.63 \\
MPD & $21.7 \%$ & $9.6 \%$ & $24.2 \%$ & $-2.7 \%$ \\
MAPD & $27.3 \%$ & $19.6 \%$ & $28.6 \%$ & $20.1 \%$ \\
\hline
\end{tabular}



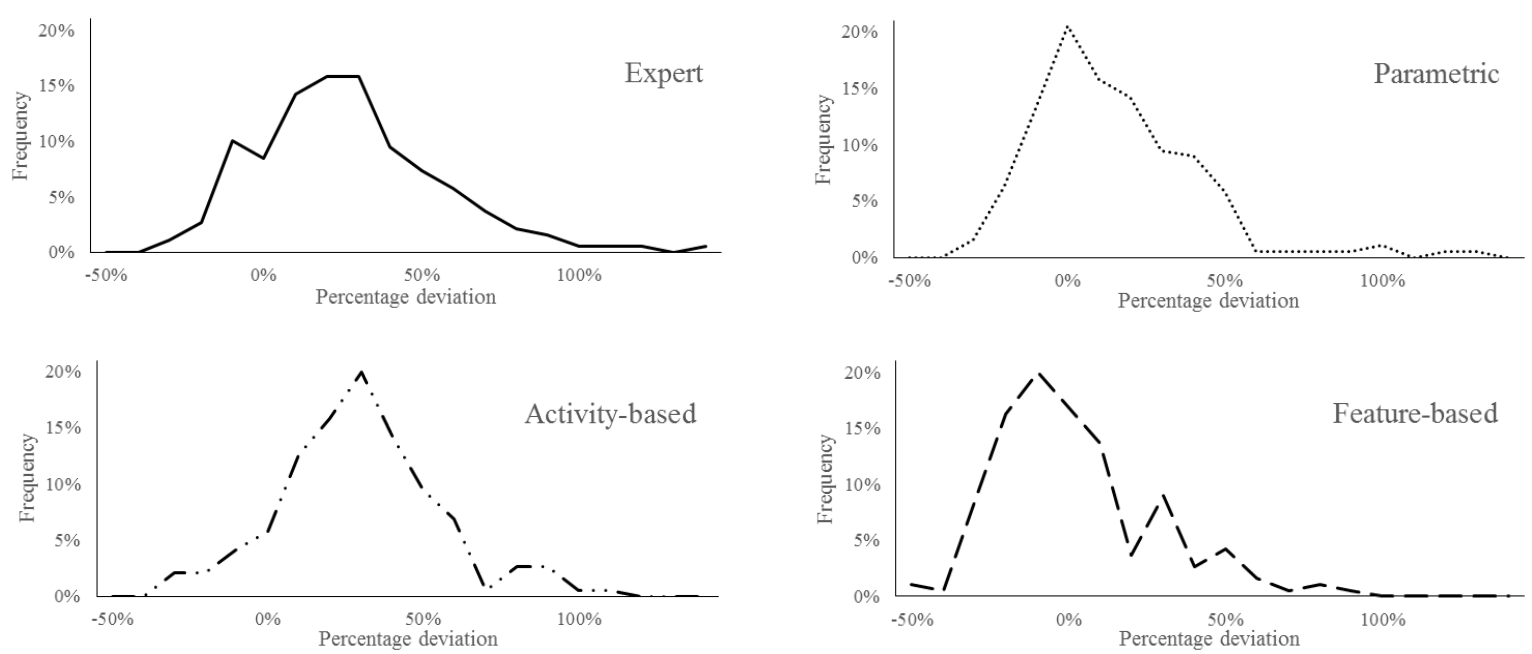

Figure 5. Distribution of the percentage deviation

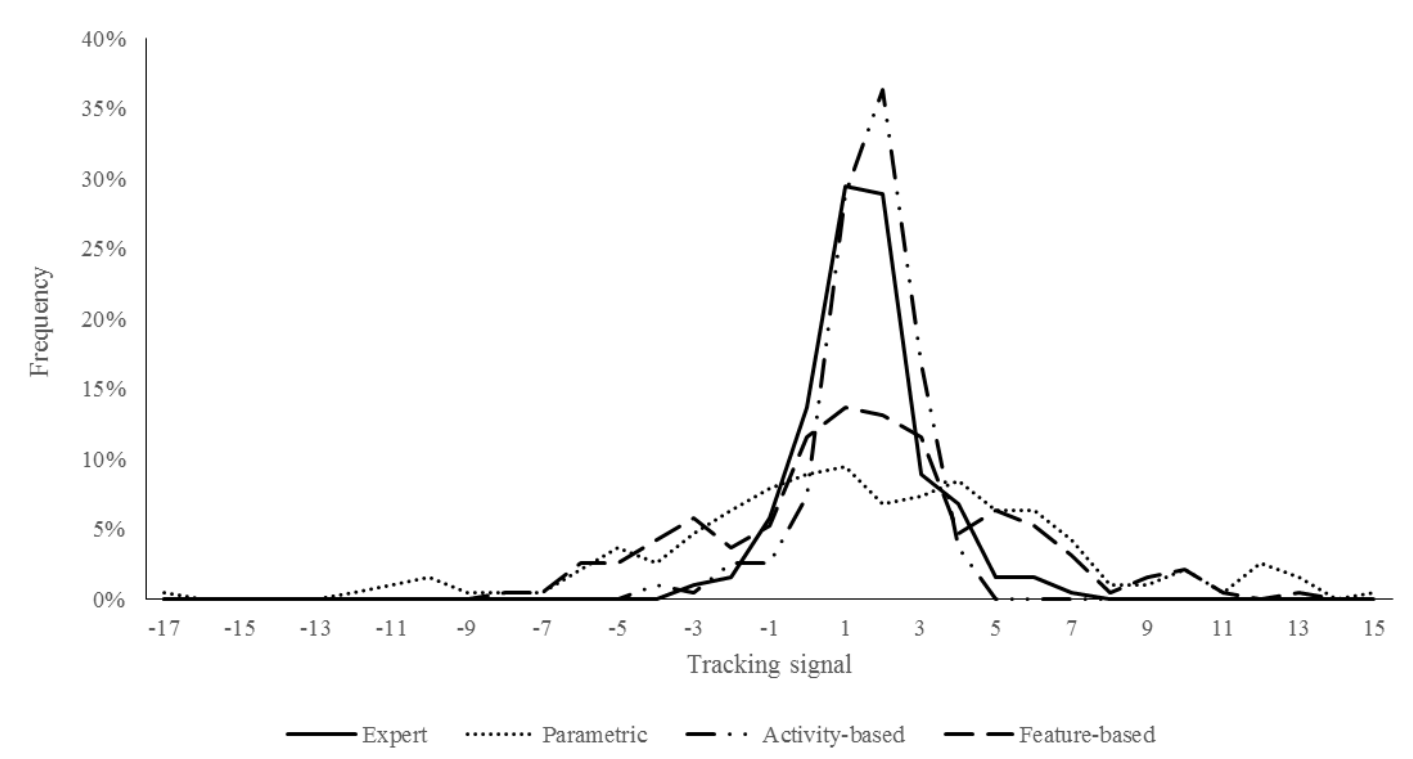

Figure 6. Distribution of the tracking signal

At this point, the thought of further improving the accuracy of the cost estimation regains focus. The obtained results show that if a combination of the three methods is used, the average accuracy level can be reduced to an excellent MAPD of $8.2 \%$. This value is obtained by using the most accurate method for each individual case and then aggregating the result. Obviously this is not practicable in the real world as one would need to know the actual costs to calculate the error rate and then use the most accurate cost estimation method, which would render the estimation useless in the first place. However, if a study could determine the correlation between the different accuracy levels of the methods and the die characteristics that determine a method's precision, then such a consensus of cost estimation methods would indeed be possible. 


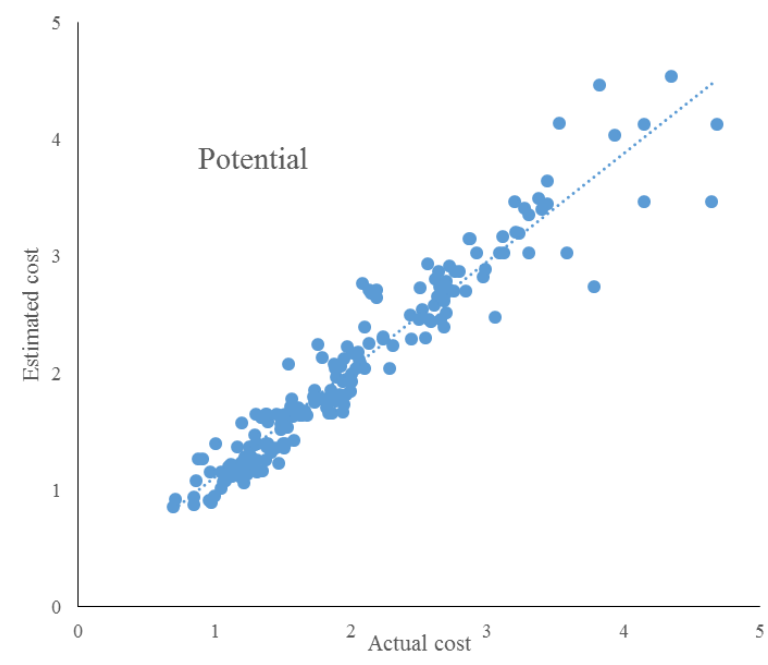

Figure 7. Potential estimates vs. actual costs

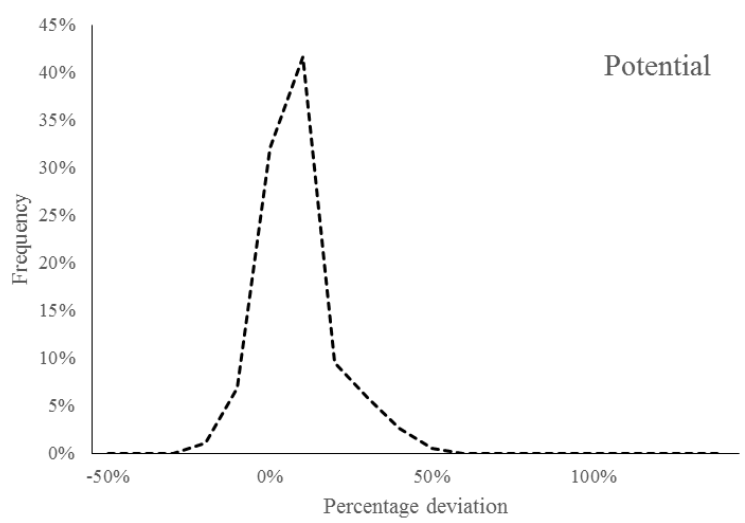

Figure 8. Distribution of the percentage deviation

Therefore, the fundamental research question of cost estimation shifts from how to improve the accuracy of the most precise cost estimation method to how to most efficiently combine the existing cost estimation methods in order to obtain the most precise estimate.

\section{Conclusion and Future Outlook}

Cost estimation within automotive die manufacturing is a complex task, and one which has been addressed for decades in the literature. The estimation of cost for die manufacturing intensifies the challenge as the product development process within this environment is complex and not easily predictable. Nevertheless, several methods designed to tackle this task have been developed, a classification of which has been presented within this paper. Variant-based, generative or hybrid cost estimation methods all have as their goal, regardless of the approach, determining the cost of manufacturing a product. The development of such a high number of methods is remarkable, considering the almost non-existent industry data source. This is reflected in the low share of methods that have been validated by researchers using real cost information. This study has additionally performed an investigation of a set of cost estimation methods on an industry data set featuring 190 dies. The results show that the most recently developed method was indeed more accurate in practice, although neither of the methods could output a stable accuracy level. In addition, a more detailed analysis revealed that an intelligent combination of cost estimation methods can lead to an improved estimation performance. Determining the factors that have an influence and which of the studied methods would potentially render the most accurate estimate is a subject for future research.

The contributions of this paper are two-fold. First, from a practical perspective, the investigation performed within the case study reveals that the currently developed methods have a good level of accuracy. As a result, their application into practice can at this stage already provide a critical advantage in the estimation and bidding procedure, 
significantly decreasing error rates and thus improving die manufacturers' chances of survival on the market. Therefore, the industry relevance of this research is of extreme importance and the support of die manufacturers in the research process is imperative in order to further improve the accuracy of cost estimation. Second, the theoretical contribution consists of identifying a research gap in the cost estimation science, namely the lack of designation of certain methods for specific applications. This article, however, does not identify the methodology for selection of the most fitting cost estimation methods, this being a subject for further research. However, the need for dedicated methods for different applications has not yet been documented and it constitutes a significant research focus that would lead to substantial leaps in the science of cost estimation, both from a practical as well as a theoretical perspective.

\section{References}

Aderoba, A. (1997). A generalised cost-estimation model for job-shops. International Journal of Production Economics, (53), 257-263. https://doi.org/10.1016/S0925-5273(97)00120-5

Agyapong-Kodua, K., Wahid, B., \& Weston, R. (2011). Towards the derivation of an integrated process cost-modelling technique for complex manufacturing systems. International Journal of Production Research, 49(24), 7361-7377. https://doi.org/10.1080/00207543.2010.535861

Ben-Arieh, D. (2000). Cost estimation system for machined parts. International Journal of Production Research, 38(17), 4481-4494. https://doi.org/10.1080/00207540050205244

Ben-Arieh, D., \& Qian, L. (2003). Activity-based cost management for design and development stage. International Journal of Production Economics, (83), 169-183. https://doi.org/10.1016/S0925-5273(02)00323-7

Bode, J. (2000). Neural networks for cost estimation: simulations and pilot application. International Journal for Production Research, 38(6), 1231-1254. https://doi.org/10.1080/002075400188825

Boons, A. N. (1998). Product costing for complex manufacturing systems. International Journal of Production Economics, (55), 241-255. https://doi.org/10.1016/S0925-5273(98)00064-4

Bouaziz, Z., Younes, J. B., \& Zghal, A. (2004). Methodology of machinng costs evaluation for die and mould manufacturing. Journal of Materials Processing Technology, (152), 237-245. https://doi.org/10.1016/j.jmatprotec.2004.04.242

Bouaziz, Z., Younes, J. B., \& Zghal, A. (2006). Cost estimation system of dies manufacturing based on complex machining features. International Journal of Advanced Manufacturing Technology, (28), 262-271. https://doi.org/10.1007/s00170-004-2179-3

Brinke, E. T., Lutters, E., Streppel, T., \& Kals, H. (2000). Variant-based cost estimation based on information management. International Journal of Production Research, 38(17), 4467-4479. https://doi.org/10.1080/00207540050205235

Chan, D., \& Lewis, W. (2000). The integration of manufacturing and cost information into the engineering design process. International Journal of Production Research, 38(17), 4413-4427. https://doi.org/10.1080/00207540050205190

Chen, M.-Y., \& Chen, D.-F. (2002). Early cost estimation of strip-steel coiler using BP neural network. Beijing, First International Conference on Machine Learning and Cybernetics. https://doi.org/10.1109/ICMLC.2002.1167420

Chin, K.-S., \& Wong, T. (1995). An expert system for injection mold cost estimation. Advances in Polymer Technology, 14(4), 303-314. https://doi.org/10.1002/adv.1995.060140404

Christou, I. T. (2011). Quantitative Methods in Supply Chain Management. London: Springer.

Cos, J. D., Sanchez, F., Ortega, F., \& Montequin, V. (2008). Rapid cost estimation of metallic components for the aerospace industry. International Journal of Production Economics, (112), 470-482. https://doi.org/10.1016/j.ijpe.2007.05.016

Crawford, G. (1985). A note on the analysis of subjective judgment matrices. Journal of Mathematical Psychology, (29), 387-405. https://doi.org/10.1016/0022-2496(85)90002-1

Curran, R., Raghunathan, S., \& Price, M. (2004). Review of aerospace engineering cost modelling: The genetic causal approach. Progress in Aerospace Sciences, (40), 487-534. https://doi.org/10.1016/j.paerosci.2004.10.001

Duverlie, P., \& Castelian, J. (1999). Cost estimation during design step: parametric method versus case based reasoning method. International Journal of Advanced Manufacturing Technology, (15), 895-906. 
https://doi.org/10.1007/s001700050147

Eversheim, W., \& Klocke, F. (1998). Werkzeugbau mit Zukunft. Berlin-Heidelberg: Springer Verlag. https://doi.org/10.1007/978-3-642-58850-1

H'mida, F., Marting, P., \& Vernadat, F. (2006). Cost estimation in mechanical production: The cost entity approach applied to integrated product engineering. International Journal of Production Economics, (103), 17-35. https://doi.org/10.1016/j.ijpe.2005.02.016

Jha, N. K. (1992). Stochastic mathematical modelling and manufacturing cost estimation in uncertain industrial environment. International Journal of Production Research, 30(12), 2755-2771. https://doi.org/10.1080/00207549208948189

Jiao, J., \& Tseng, M. M. (1999). A pragmatic approach to product costing based on standard time estimation. International Journal of Operations and Production Management, 19(7), 738-755. https://doi.org/10.1108/01443579910271692

Jo, H. H., Parsael, H. R., \& Wong, J. P. (1991). Concurrent Engineering: The manufacturing philosophy for the 90's. Computers industrial Engineering, 21(1-4), 35-39. https://doi.org/10.1016/0360-8352(91)90059-F

Jung, J.-Y. (2002). Manufacturing cost estimation for machined parts based on manufacturing features. Journal of Intelligent Manufacturing, (13), 227-238. https://doi.org/10.1023/A:1016092808320

Kingsman, B. G., \& Souza, A. A. d. (1997). A knowledge-based decision support system for cost estimation and pricing decisions in versatile manufacturing companies. International Journal of Production Economics, (53), 119-139. https://doi.org/10.1016/S0925-5273(97)00116-3

Layer, A. (2003). Case-based cost estimation: a building block for product cost management and design-for-x. s.1.:s.n.

Nagahanumaiah, Ravi, B., \& Mukherjee, N. (2005). An integrated framework for die and mold cost estimation usign design features and tooling parameters. International Journal for Advanced Manufacturing Technology, (26), 1138-1149. https://doi.org/10.1007/s00170-004-2084-9

Ong, N. (1995). Manufacturing cost estimation for PCB assembly: an activity-based approach. International Journal for Production Economics, (38), 159-172. https://doi.org/10.1016/0925-5273(94)00089-S

Ou-Yang, C., \& Lin, T. (1997). Developing and integrated framework for feature-based early manufacturing cost estimation. International Journal of Advanced Manufacturing Technology, (13), 618-629. https://doi.org/10.1007/BF01350820

Qian, L., \& Ben-Arieh, D. (2008). Parametric cost estimation based on activity-based costing: A case study for design and development of rotational parts. International Journal of Production Economics, (113), 805-818. https://doi.org/10.1016/j.ijpe.2007.08.010

Schreve, K., Schuster, H., \& Basson, A. (1999). Manufacturing cost estimation during design of fabricated parts. s.l., s.n. https://doi.org/10.1243/0954405991517146

Schuh, G., Pitsch, M., Kühn, T., \& Kelzenberg, C. (2005). Industrialization of the Tool and Die Industry. Kusadasi, Turkey, 8th International Conference and Exhibition on Design and Production of Machines and Dies/Molds.

Schuler. (1998). Handbuch der Umformtechnik. Berlin Heidelberg: Springer-Verlag.

Shehab, E., \& Abdalla, H. (2001). Manufacturing cost modelling for concurrent product development. Robotics and Computer Integrated Manufacturing, (17), 341-353. https://doi.org/10.1016/S0736-5845(01)00009-6

Shepperd, M., \& Schofield, C. (1997). Estimating software project effort using analogies. IEEE Transactions on software engineering, 23(12). https://doi.org/10.1109/32.637387

Shepperd, M., Schofield, C., \& Kitchenham, B. (1996). Effort estimation using analogy. s.1., s.n. https://doi.org/10.1109/ICSE.1996.493413

Syan, C. S., \& Menon, U. (1994). Concurent Engineering: Concepts, implementation and practice. s.1.:Springer. https://doi.org/10.1007/978-94-011-1298-7

Tornberg, K., Jämsen, M., \& Paranko, J. (2002). Activity-based costing and process modeling for cost-conscious product design: a case study in a manufacturing company. International Journal of Production Economics, (79), 75-82. https://doi.org/10.1016/S0925-5273(00)00179-1 
Tumis, S. (2007). Cost Calculation of Dies and Molds: Challenges, Developments and Future Trends. Cesme, Turkey, s.n.

Verlinden, B., J.R.Duflou, Collin, P., \& Cattrysse, D. (2008). Cost estimation for sheet metal parts using multiple regression and artificial neural networks: a case study. International Journal for Production Economics, (111), 484-492. https://doi.org/10.1016/j.ijpe.2007.02.004

Wei, Y., \& Egbelu, P. J. (2000). A framework for estimating manufacturing cost from geometric design data. International Journal for Computer Integrated Manufacturing, 13(1), 50-63. https://doi.org/10.1080/095119200130054

Weustink, I., Brinke, E. t., Streppel, A., \& Kals, H. (2000. A generic framework for cost estimation and cost control in product design. Journal of Materials Processing Technology, (103). https://doi.org/10.1016/S0924-0136(00)00405-2

Zhang, Y., \& Fuh, J. (1998. A neural network approach for early cost estimation of packaging products. Computers industrial Engineering, 34(2), 433-450. https://doi.org/10.1016/S0360-8352(97)00141-1 